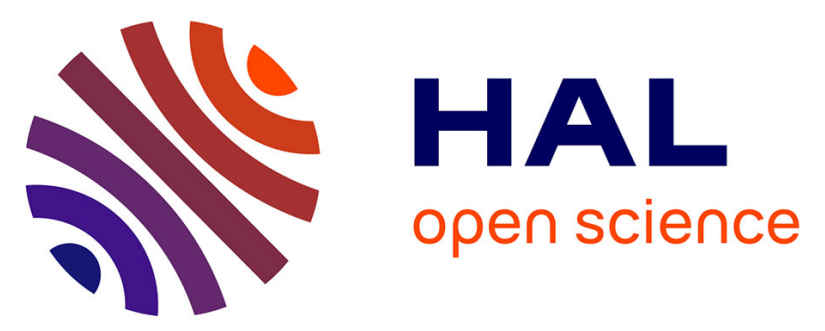

\title{
Inhibition of platelet activation prevents the P-selectin and integrin-dependent accumulation of cancer cell microparticles and reduces tumor growth and metastasis in vivo
}

\author{
Soraya Mezouar, Roxane Darbousset, Francoise Dignat-George, Laurence \\ Panicot-dubois, Christophe Dubois
}

\section{To cite this version:}

Soraya Mezouar, Roxane Darbousset, Francoise Dignat-George, Laurence Panicot-dubois, Christophe Dubois. Inhibition of platelet activation prevents the P-selectin and integrin-dependent accumulation of cancer cell microparticles and reduces tumor growth and metastasis in vivo. International Journal of Cancer, 2015, 136 (2), pp.462-475. 10.1002/ijc.28997 . hal-01773064

\section{HAL Id: hal-01773064 \\ https://hal-amu.archives-ouvertes.fr/hal-01773064}

Submitted on 20 Apr 2018

HAL is a multi-disciplinary open access archive for the deposit and dissemination of scientific research documents, whether they are published or not. The documents may come from teaching and research institutions in France or abroad, or from public or private research centers.
L'archive ouverte pluridisciplinaire HAL, est destinée au dépôt et à la diffusion de documents scientifiques de niveau recherche, publiés ou non, émanant des établissements d'enseignement et de recherche français ou étrangers, des laboratoires publics ou privés. 


\title{
Inhibition of platelet activation prevents the P-selectin and integrin-dependent accumulation of cancer cell microparticles and reduces tumor growth and metastasis in vivo
}

\author{
Soraya Mezouar ${ }^{1}$, Roxane Darbousset ${ }^{1}$, Françoise Dignat-George ${ }^{1,2}$, Laurence Panicot-Dubois ${ }^{1}$ and Christophe Dubois $^{1}$ \\ ${ }^{1}$ Aix Marseille Université, INSERM UMR-S1076, 13385 Marseille, France \\ 2Laboratoire d'Hématologie, Centre Hospitalo-Universitaire Conception, 13385 Marseille, France
}

\begin{abstract}
Venous thromboembolism constitutes one of the main causes of death during the progression of a cancer. We previously demonstrated that tissue factor (TF)-bearing cancer cell-derived microparticles accumulate at the site of injury in mice developing a pancreatic cancer. The presence of these microparticles at the site of thrombosis correlates with the size of the platelet-rich thrombus. The objective of this study was to determine the involvement of TF expressed by cancer cell-derived microparticles on thrombosis associated with cancer. We observed that pancreatic cancer cell derived microparticles expressed TF, its inhibitor tissue factor pathway inhibitor (TFPI) as well as the integrins $\alpha \mathrm{v} \beta 1$ and $\alpha \mathrm{v} \beta 3$. In mice bearing a tumor under-expressing TF, a significant decrease in circulating TF activity associated with an increase bleeding time and a 100 -fold diminished fibrin generation and platelet accumulation at the site of injury were observed. This was mainly due to the interaction of circulating cancer cell-derived microparticles expressing TFPI with activated platelets and fibrinogen. In an ectopic model of cancer, treatment of mice with Clopidogrel, an anti-platelet drug, decreased the size of the tumors and restored hemostasis by preventing the accumulation of cancer cell-derived microparticles at the site of thrombosis. In a syngeneic orthotopic model of pancreatic cancer Clopidogrel also significantly inhibited the development of metastases. Together, these results indicate that an anti-platelet strategy may efficiently treat thrombosis associated with cancer and reduce the progression of pancreatic cancer in mice.
\end{abstract}

Since its first clinical description by Armand Trousseau in 1865, the association between cancer and thrombosis has been well documented. ${ }^{1}$ Venous thromboembolism (VTE), defined as deep vein thrombosis and/or pulmonary embolism (PE), occurs in $15-20 \%$ of patients with cancer. ${ }^{2}$ VTE constitutes one of the main causes of death during the progression of cancer (with a relative risk ranging from 4 to 7 ) and rep-

Key words: pancreatic cancer, thrombosis, platelets, tissue factor, microparticles

Additional Supporting Information may be found in the online version of this article.

Conflict of interest: The authors have no conflicts to disclose. Grant sponsors: GFTC (Groupe Francophone Thrombose et Cancer), the ARC (Agence pour la Recherche sur le Cancer) and the FRM (Foundation pour la Recherche Médicale) associations (grants to C. D.); Grant sponsors: the institutional funding from INSERM, the Aix-Marseille University and the ANR (Agence Nationale pour la Recherche; Grant number: ANR-09-JCJC-0053 [to C. D.]). DOI: $10.1002 /$ ijc. 28997

History: Received 23 Dec 2013; Accepted 20 May 2014; Online 29 May 2014

Correspondence to: Christophe Dubois, AMU, INSERM UMR-

S1076, 27 Boulevard Jean Moulin, 13385 Marseille, France,

Tel.: +33-491835561, Fax: +33-491835602,

E-mail: christophe.dubois@univ-amu.fr resents a major therapeutic issue. The risk of thrombosis is increased in patients with digestive adenocarcinoma, pancreatic adenocarcinomas, lung or ovarian cancer and acute promyelocytic leukemia. ${ }^{3-5}$ Among these cancers, thromboembolic diseases are the second most common cause of death, accounting for $44 \%$ of deaths after the progression of the cancer itself. ${ }^{6,7}$ Patients with cancer who develop a VTE have a lower survival rate. ${ }^{8}$ Several studies have been performed recently to understand the cellular mechanisms involved in the development of thromboembolic events. The pathogenesis of a thrombotic state is linked to the presence of a tumor and is associated with the development of a hypercoagulant state, referred to as coagulopathy that confers numerous advantages to the cancer cells. Indeed, both the activation of the coagulation cascade and the aggregation of blood platelets around cancer cells protect these cells from the immune system and facilitate their circulation in the bloodstream and their adhesion at potential sites of metastasis. ${ }^{9,10}$ In addition to its role in the activation of coagulation, the TF/FVIIa complex also influences pathways that activate cell-bound protease-activated receptors (PARs), leading to the activation of inflammatory and angiogenic responses. ${ }^{11}$ These processes lead to a model in which the presence of tissue factor (TF), the generation of thrombin and the activation of platelets all directly participate in the progression of the cancer. In addition, the presence of TF and the activation of platelets participate in the progression of the tumor. ${ }^{12}$ Thus, it is 


\section{What's new?}

Tissue factor (TF) plays a key role in coagulation and is capable of activating inflammatory and angiogenic responses, potentially facilitating the progression of cancer. As a result, anticoagulant or antiplatelet drugs could be effective means of prevention for tumor progression and metastasis. Here, pancreatic cancer cell-derived microparticles were found to express TF and its inhibitor TFPI. The microparticles interacted with platelets, with effects on bleeding and platelet accumulation, in mice. In cancer mouse models, treatment with the antiplatelet drug clopidogrel restored hemostasis, resulted in decreased tumor size, and prevented the development of metastases.

logical to hypothesis that treatment with anticoagulant or antiplatelet drugs may prevent, in addition to coagulopathy, progression of a tumor and formation of metastasis. However, in the absence of clear data in the literature, these drugs are not indicated in the prevention of venous thromboembolic events or in treatment for cancer.

We previously demonstrated the key role of TF-bearing cancer cell-derived microparticles in thrombosis associated with cancer. ${ }^{13}$ We found that both endogenously generated and exogenously injected pancreatic cancer cell-derived microparticles expressing TF (Panc02), but not their parental tumor cells, accumulated at the site of injury in a P-selectindependent manner. The presence of these microparticles directly correlated with the size of the thrombus. Based on these data, we hypothesized that treatment with anticoagulant or antiplatelet drugs may prevent tumor progression and the formation of metastases, in addition to coagulopathy. Here, we showed in syngeneic ectopic and orthotopic mice models that treatment with Clopidogrel prevented the binding of cancer cell-derived microparticles to fibrinogen-platelets aggregates at the site of thrombosis, thereby suppressing the development of the tumor and reducing metastasis and the extent of thrombosis associated with cancer.

\section{Material and Methods \\ Mice}

Wild-type C57BL/6J mice were obtained from Janvier Elevage and were housed under standard conditions. All of the animal care and experimental procedures were performed as recommended by the European Community guidelines and were approved by the local ethical committee number 14 (number 11102012).

\section{Antibodies and reagents}

Rabbit anti-mouse TF IgG (Abcam, ab17375), rabbit antimouse Tissue Factor Pathway Inhibitor (TFPI) IgG (American Diagnostica), Alexa Fluor 594-conjugated anti-rabbit IgG (Life Technologies) and HRP-linked Ab anti-rabbit IgG (Cell Signaling) were used in vitro for western blotting and immunofluorescence. PE-conjugated hamster anti-mouse CD61, hamster anti-mouse CD29, rat anti-mouse CD51 and appropriated isotypes controls were used to perform flow cytometry experiments (BD Bioscience). For the in vivo experiments, a rat anti-mouse CD41 antibody (Emfret analytics), a rat anti-mouse $\mathrm{P}$-selectin antibody (BD Bioscience) and a mouse anti-fibrin antibody were labeled and used as previously described. ${ }^{14}$ R300 antibody used to deplete circulating platelets was obtained from Emfret anaytics. Arg-Gly-Asp-Val peptide was purchased from Polypeptide. The microparticles were labeled using DIO (iodide of (dodecyl-4 aminostyryl) -4 $\mathrm{N}$ - methylpyridium) Vybrant ${ }^{\mathrm{TM}}$ kit (Molecular Probes).

\section{Cell culture}

The mouse pancreatic cancer cell line Panc02, originally established by Corbett et al. ${ }^{15}$, was generously given to our laboratory by Ruben Hernandez-Alcoceba (University of Navarra, Pamplona, Spain). Panc02 cells and Panc02-GFP cells $^{13}$ were grown in RPMI-1640 medium (Life Technologies) supplemented with $10 \%$ FCS (PAA), $100 \mathrm{U} / \mathrm{mL}$ penicillin (Life Technologies), $100 \mu \mathrm{g} / \mathrm{mL}$ streptomycin (Life Technologies) and $0.1 \%$ fungizone (Life Technologies). The cells were grown at $37^{\circ} \mathrm{C}$ in a humidified atmosphere with $5 \% \mathrm{CO}_{2}$.

\section{Cell transfection}

Panc02 cells were stably transfected with the pGL4.51[luc2/ $\mathrm{CMV} / \mathrm{Neo}$ ] vector (Promega), the $\mathrm{pcDNA}^{\mathrm{TM}}$ 6.2-GW/ EmGFP-miR mock or the pcDNA ${ }^{\mathrm{TM}}$ 6.2-GW/EmGFP-miR Tissue Factor plasmids (Life Technologies) using Lipofectamine 2000 and PLUS reagent (Life Technologies) according to the manufacturer's recommendations (Life Technologies). After 2 months of selection using G418. One clone was selected based on its luminescence activity and was named Panc02-Luci. Two other clones selected one coding for miRNA directed against the tissue factor and associated with the expression of the GFP, and a its control coding for miRNA directed against a scramble were selected based on their GFP expression and named Panc02-Low TF and Panc02-HighTF, respectively.

\section{Isolation of microparticles}

The isolation of microparticles was performed as previously described. $^{13}$

\section{Preparation of Platelets-Poor Plasma containing microparticles}

Blood was collected from tumor-free mice and mice bearing a tumor in a citrate solution (ACD: $85 \mathrm{mM}$ trisodium citrate, $67 \mathrm{mM}$ citric acid, $111.5 \mathrm{mM}$ glucose, $\mathrm{pH} 4.5)$ in the 
presence of $0.5 \mathrm{mM}$ prostacyclin (PGI2; Calbiochem-Novabiochem) and $0.02 \mathrm{U} / \mathrm{mL}$ apyrase (Sigma-Aldrich). Citrated blood was centrifuged at $200 \mathrm{~g}$ for $12 \mathrm{~min}$ to obtain PlateletsRich Plasma (PRP). Platelets-Poor Plasma (PPP) was obtained after centrifugation of PRP at $1,100 \mathrm{~g}$ for $10 \mathrm{~min}$, following addition of PGI2 to prevent platelets activation. PPP was then centrifuged at 7,000 $\mathrm{g}$ for $3 \mathrm{~min}$. Aliquots were snap-frozen in liquid nitrogen and stored at $-80^{\circ} \mathrm{C}$.

\section{Flow cytometry}

The expression of AnnexinV, GFP and the beta1, beta3 and alphav subunits at the surface of Panc02 clones and their microparticles was analyzed using a Gallios flow cytometer (Beckman Coulter). The flow cytometry instrument settings and microparticles gating were performed with Megamix beads. Briefly, PPP or purified microparticles suspension were incubated 40 min with FITC-annexin V and PE-anti mouse antibodies (anti-CD29; anti-CD51 and anti-CD61). All the data analyses were performed with the software Kaluza.

\section{RT-PCR}

The presence of TF mRNA in the Panc02-HighTF and Panc02-LowTF clones was detected by RT-PCR (Promega).

\section{Immunofluorescence}

The cells were grown to $80 \%$ confluence in an eight-chamber glass system (Thermo Fisher Scientific), washed with PBS, and fixed for $30 \mathrm{~min}$ at $4^{\circ} \mathrm{C}$ in PBS containing $2 \%$ paraformaldehyde. Once fixed, the cells were incubated for $1 \mathrm{hr}$ with blocking buffer (PBS, 1\% BSA, 0.05\% saponin) at room temperature. Cell nuclei were labeled with 4',6-diamidino-2-phenylindole (DAPI), and the cells were incubated with or without a TF antibody and with an Alexa Fluor 488conjugated secondary antibody. Between each step, the cells were extensively washed with PBS. The stained cells were visualized using a fluorescence microscope and analyzed using SlideBook 5.0 software (3I).

\section{PAGES and western blotting}

SDS-PAGE (4-20\%) and western blotting were performed as previously described. ${ }^{16}$

\section{TF and TFPI activity assay}

A chromogenic assay (Actichrome TF and TFPI activity assay; American Diagnostica) was used to analyze TF and TFPI activity according the manufacturer's instructions. The absorbance was read at $405 \mathrm{~nm}$ with a microplate reader (MR5000; Dynatech). The TF and TFPI concentrations were determined by interpolation from a standard curve constructed using different amounts of lipidated TF and TFPI standards.

\section{Flow chamber}

All the flow chamber experiments were performed with the IBIDI pump system. Briefly, $\mu$-Slides-ibidi-treated were coated with fibrinogen or PBS for $30 \mathrm{~min}(40 \mu \mathrm{g} / \mathrm{mL}$; Sigma
Aldrich). Labeled microparticles $\left(2 \times 10^{5}\right)$ were infused in $\mu$ slides. Shear rate were applied through an air-driven continuous flow pump system controlled by a computer with the PumpControl Software. ${ }^{17}$

\section{Ectopic tumors induction}

Panc02 cells were cultured to $80 \%$ confluence and, once in the exponential growth phase, were washed three times with PBS and briefly exposed to nonenzymatic cell dissociation buffer (Life Technologies) to dislodge the cells. The cells were carefully washed three times, resuspended in PBS, and diluted to the desired concentration. Five-week-old C57BL/6 mice were injected subcutaneously in the right flank with a tumor cell suspension $\left(10^{6}\right.$ cells in $100 \mu \mathrm{L}$ of PBS $\left.-/-\right)$. When the tumor became palpable $(0.2 \mathrm{~cm})$, measurements in two dimensions were performed with a caliper, and the volume of each tumor was calculated according to the formula for the volume of an ellipsoid: $\pi / 6 \times a\left(b^{2}\right)$, where $a$ is the largest diameter and $b$ the smallest diameter of the tumor.

\section{Orthotopic tumors induction}

Panc02-Luci cells were cultured to $80 \%$ confluence and, once in the exponential growth phase, were washed three times with PBS and briefly exposed to nonenzymatic cell dissociation buffer to dislodge the cells. The cells were carefully washed three times, resuspended in RPMI medium and diluted to the desired concentration. The Panc02-Luci cells were kept on ice until injection. Five-week-old C57BL/6 mice were anesthetized with an intraperitoneal injection of ketamine (125 mg/kg; Panpharma), xylazine (12.5 mg/kg; Bayer) and atropine $(0.25 \mathrm{mg} / \mathrm{kg}$; Lavoisier $)$. The peritoneal cavity was opened, and a mixture containing a tumor cell suspension $\left(2 \times 10^{6}\right.$ cells in $50 \mu \mathrm{L}$ of RPMI medium) and $50 \mu \mathrm{L}$ of Matrigel (BD Bioscience) was injected into the head of the pancreas, as previously described. ${ }^{18}$ Temgesic was subcutaneously administered to mice $(0.025 \mathrm{mg} / \mathrm{kg})$ just after the surgery and $24 \mathrm{hr}$ later. Mice were daily observed and treated with Buprenorphin (up to $2.5 \mathrm{mg} / \mathrm{kg}$ ) as soon as distinctive pain signs were detected.

\section{Clopidogrel, low-molecular-weight heparin and aspirin treatment}

Two days after the induction of ectopic tumors and 7 days after induction of orthotopic tumors, the mice were randomly divided into several groups (with at least eight mice/group). For the duration of the experiment, the mice received daily per os $200 \mu \mathrm{L}$ of $0.09 \% \mathrm{NaCl}$ (control group), Clopidogrel at $8 \mathrm{mg} /$ $\mathrm{kg}$ in a final volume of $200 \mu \mathrm{L}$ (Clopidogrel group) or Aspirin at $10 \mathrm{mg} / \mathrm{kg}$ in a final volume of $200 \mu \mathrm{L}$ (Aspirin group). Another group of mice received $0.1 \mathrm{mg} / \mathrm{kg}$ low molecular weight heparin (LMWH) subcutaneously (LMWH group).

\section{In vivo bioluminescence imaging}

Prior to the in vivo imaging, the mice were anesthetized with an intraperitoneal injection of ketamine $(125 \mathrm{mg} / \mathrm{kg}$; 
a

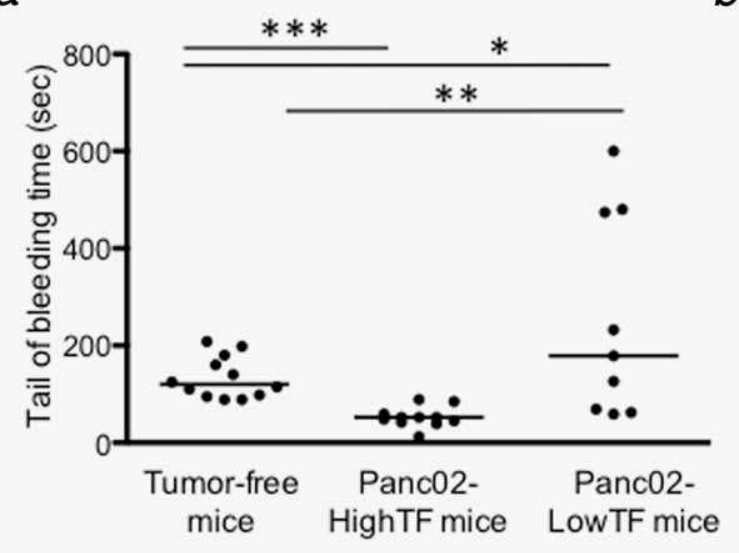

$b$

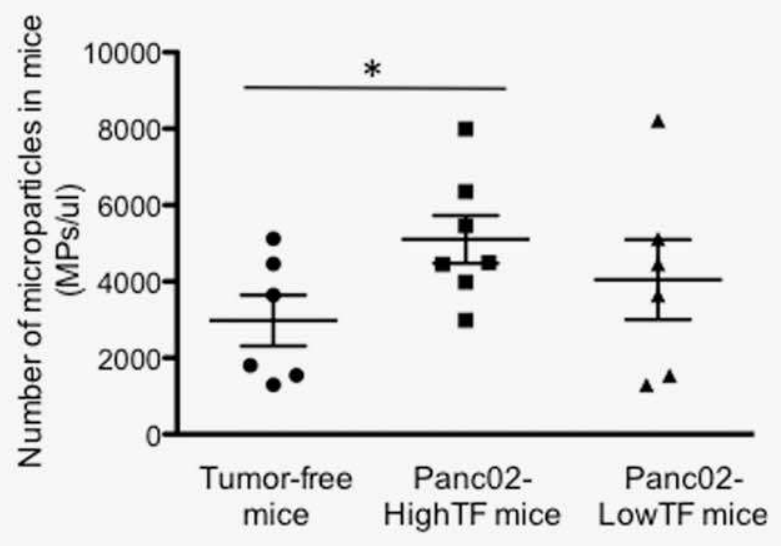

C

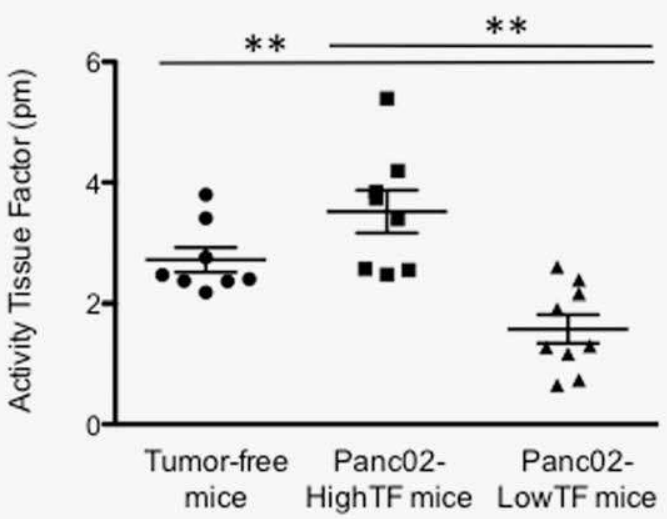

e mice HighTF mice LowTF mice

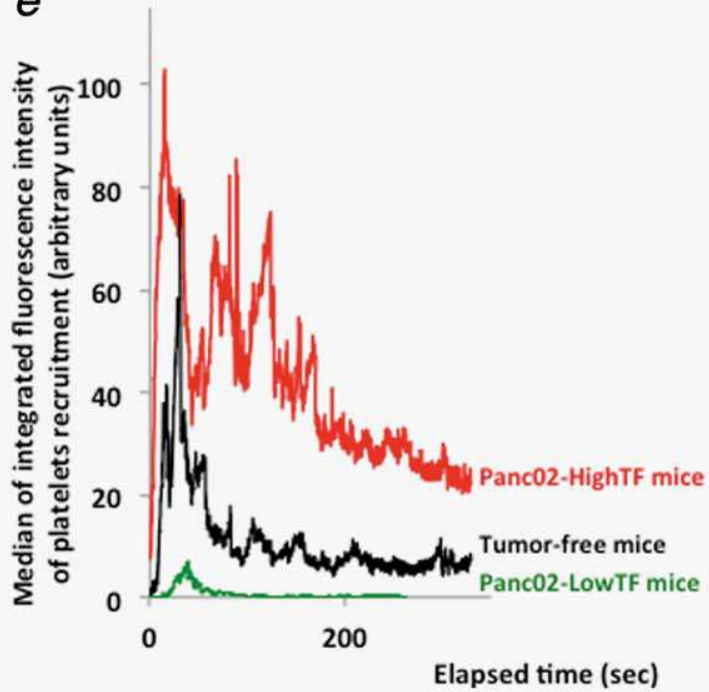

$d$

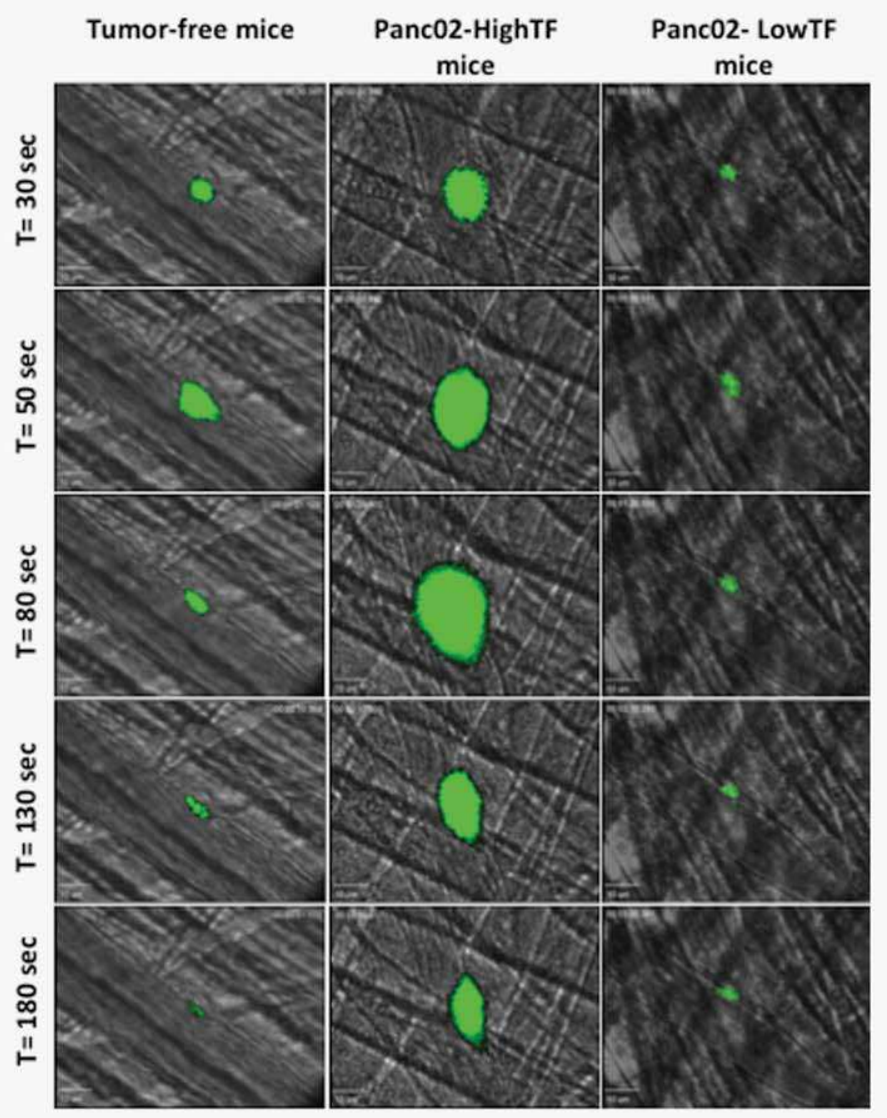

Figure 1. Involvement of TF expressed at the surface of Panc02 cells on hemostasis and thrombosis in a syngeneic ectopic model of pancreatic cancer in mice. (a) Tail bleeding times for tumor-free mice $(N=12)$, mice bearing Panc02-HighTF ectopic tumors $(N=11)$ and mice bearing Panc02-LowTF ectopic tumors $(N=9)$. (b) Number of Annexin-V positive microparticles detected by FACS-analysis present in the plasma of tumor-free mice $(N=6)$, mice bearing Panc02-HighTF ectopic tumors $(N=7)$ and mice bearing Panc02-LowTF ectopic tumors $(N=6)$. (c) Concentration in active tissue factor present in the plasma of tumor-free mice $(N=8)$, mice bearing Panc02-HighTF ectopic tumors $(N=8)$ and mice bearing Panc02-LowTF ectopic tumors $(N=8)$. (d) Representative images of thrombus formation obtained by intravital microscopy in tumor-free mice or mice bearing Panc02-HighTF or Panc02-LowTF tumors. Following laser-induced injury, the kinetics of thrombosis were evaluated based on the platelet accumulation (depicted in green) at different time points during thrombus formation by the infusion of a rat anti-mouse platelet CD41 antibody (Emfret Analytics). (e) The graph depict the median integrated fluorescence intensity of platelets as a function of time in thrombi after laser-induced injury in tumor-free mice ( 43 thrombi in 4 mice), Panc02-HighTF ( 42 thrombi in 4 mice) and Panc02-LowTF mice (46 thrombi in 4 mice). ${ }^{*} p<0.05 ;{ }^{\star \star} p<0.01$; ${ }^{\star \star \star} p<0.001$. [Color figure can be viewed in the online issue, which is available at wileyonlinelibrary.com.] 
Panpharma), xylazine (12.5 mg/kg; Bayer) and atropine (0.25 mg/kg; Lavoisier) and were given D-luciferin (Molecular Probes) by intraperitoneal injection $(150 \mu \mathrm{g} / \mathrm{mL})$. The bioluminescence signal of the tumor was measured 20 days after the injection of the tumor cells using an in vivo bioluminescence imaging system (Biospace, Paris, France). The luciferase bioluminescence activity was measured for $10 \mathrm{~min}$ first on the ventral face of the animal, and next on the spleen, the bowel, the lungs and the kidneys using a Photon Imager (Biospace).

\section{Intravital microscopy and laser-induced injury}

Intravital video microscopy of the cremaster muscle microcirculation was performed as previously described using SlideBook (Intelligent Imaging Innovation). ${ }^{16}$ Vessel wall injury was induced with a MicroPoint Laser System (Photonics Instruments) focused through the microscope's objective, parfocal with the focal plane and aimed at the vessel wall, as previously described. ${ }^{19}$ The analyses were performed using SlideBook software as described previously by Dubois et al. ${ }^{20}$

\section{Tail bleeding time}

Mouse tail bleeding times were determined as previously described. ${ }^{16}$ The investigator was blinded to the genotype or to treatments of the mice. Briefly, a 1 - to $3-\mathrm{mm}$ portion of the distal tail was removed from a 6 - to 8 -week-old mouse; the tail was immersed in isotonic saline $\left(37^{\circ} \mathrm{C}\right)$, and the time to complete cessation of blood flow recorded. The bleeding time was monitored for a maximum of $10 \mathrm{~min}$.

\section{Statistics}

For in vitro experiments, significance was determined using the paired two-tailed Student's $t$ test. For the in vivo experiments, significance was determined using Wilcoxon's ranksum test as previously described. ${ }^{13,16,19,20}$ For the measure of the tumor volume, significance was determined using MannWhitney test. The differences were considered to be significant at $p<0.05$.

\section{Results}

Knockdown of TF expressed at the surface of Panc02 affects tumor growth, hemostasis and thrombosis in a syngeneic ectopic model of pancreatic cancer in mice

Tissue factor (TF) is both a main effector of the coagulation cascade and a protein involved in the development of solid tumors. $^{21}$ To determine the involvement of TF expressed by cancer cells, in thrombosis associated with cancer, we developed two different stables clones as described in "Material and Methods" section named Panc02-LowTF and Panc02-HighTF. The reductions in the expression of TF determined by RT-PCR and immunofluorescence were 85 and 95\%, respectively, in the Panc02-LowTF cells in comparison with the Panc02-HighTF cells (Supporting Information Figs. $1 a$ and $1 b$ ). Although the growth characteristics and the total number of microparticles expressed by the two transfected cell clones (Supporting Infor- mation Figs. $2 a$ and $2 b$ ) were similar, the activity of TF was decreased by up to $25 \%$ in the Panc02-LowTF cells (Supporting Information Fig. 2c). As previously described in xenogeneic models of cancers, ${ }^{22}$ when using the Panc02-LowTF cells, the growth of the tumors in mice was reduced by $75 \%$ in comparison with the growth of tumors in mice injected with Panc02HighTF cells (Supporting Information Figs. $3 a$ and $3 b$ ). Together, these results indicate that the Panc02-LowTF and Panc02-HighTF clones can be used as models to study the effects of TF expression by cancer cells and cancer cell-derived microparticles on thrombosis.

To understand the contribution of TF expressed by cancer cells to the hemostatic process in vivo, we explored its effect on primary hemostasis by comparing the bleeding times of mice bearing Panc02-HighTF or Panc02-LowTF tumors and wild-type mice. As previously demonstrated, ${ }^{13}$ the bleeding time was significantly reduced for mice bearing Panc02HighTF tumors in comparison with wild-type mice. However, although Panc02-LowTF-bearing mice exhibited no evidence of spontaneous bleeding or hemorrhage, the median time to bleeding cessation was significantly prolonged $(p<0.0002)$ in these mice compared with wild-type mice (Fig. 1a). This effect was not attributed to alterations in the platelet count, as wild-type mice injected with Panc02HighTF or Panc02-LowTF cells had similar platelet numbers (data not shown). However, although the quantity of circulating microparticles was identical is mice bearing a Panc02Low and HighTF tumor (Fig. 1b), the activity of plasmatic TF was significantly decreased when the protein was knockdown from the cancer cells (Fig. 1c).

We next examined the kinetics of arteriolar thrombus development in real time in the cremaster microcirculation of wild-type mice bearing Panc02-LowTF or Panc02-HighTF tumors or no tumors. Thrombus formation was initiated by laser-induced injury of the arteriolar vessel wall. In tumorfree mice, platelets adhered and accumulated at the site of injury. The thrombus increased in size rapidly between 15 and $90 \mathrm{sec}$ after injury and then decreased in size and stabilized at 3-4 min after injury (Figs. $1 d$ and $1 e$ ), as previously observed. ${ }^{13}$ Platelets accumulated more rapidly at the site of injury and the thrombus reached a larger size in mice with Panc02-HighTF tumors than in tumor-free mice. Surprisingly, in mice with tumors induced by Panc02-LowTF cells, the rates of platelet accumulation at the sites of injury were significantly slower in comparison with tumor-free mice (Figs. $1 d$ and $1 e$ ). Together, our results indicate that the specific inhibition of TF expression by cancer cells and their microparticles may affect hemostasis and thrombosis in mice even though the tumor is still present.

\section{Treatment with Clopidogrel reduces thrombosis and inhibits tumor growth without inducing prolonged bleeding time}

We next compared the effects of an inhibitor of platelet activation, Clopidogrel, and an inhibitor of the activation of the 

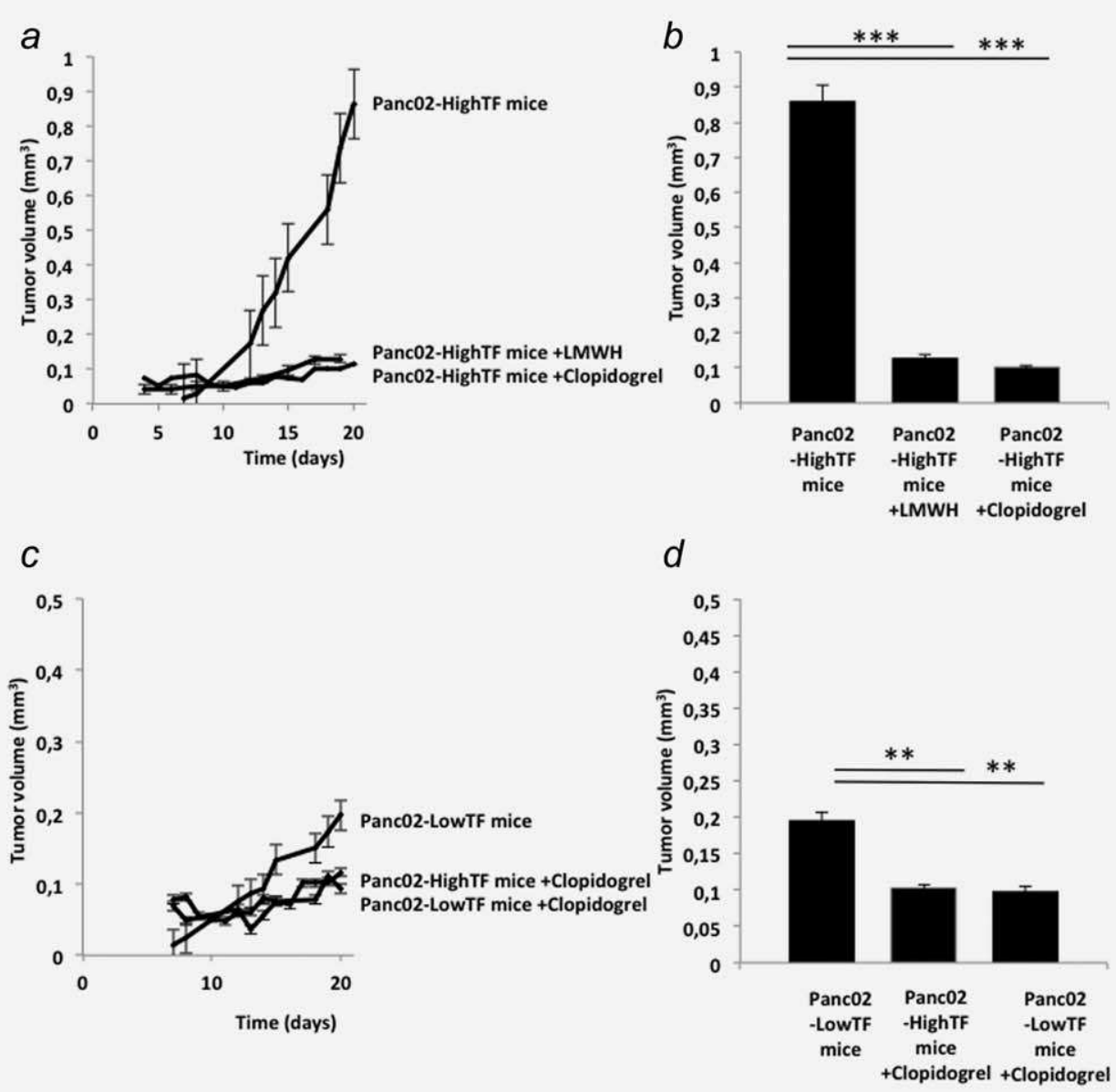

Figure 2. Treatment with Clopidogrel reduces tumor growth. $(a, b)$ The growth of the tumors over time $(a)$ and mean volume of the tumors at day $20(b)$ were evaluated in mice bearing ectopic tumors induced by Panc02-HighTF cells and treated or not $(N=10)$ with Clopidogrel $(N=9,8 \mathrm{mg} / \mathrm{kg}$ daily) or low-molecular-weight heparin $(N=11,0.5 \mathrm{mg} / \mathrm{kg}$ mouse, daily). $(c, d)$ The kinetics of tumor growth $(c)$ and mean tumor volume at day $20(d)$ for mice ectopically injected with Panc02-LowTF cells $(N=12)$ or Panc02-HighTF cells $(N=10)$ or injected with Panc02-LowTF cells and treated with Clopidogrel $(N=13) .{ }^{\star \star} p<0.01 ;{ }^{* \star *} p<0.001$.

coagulant cascade, LMWH, on tumor growth and thrombosis associated with cancer. The concentrations of the drugs used were calculated to induce a $50 \%$ reduction in thrombus formation following laser-induced injury in healthy mice (data not shown). In vitro, Clopidogrel and LMWH did not affect the growth of the Panc02 clones (data not shown). The two drugs were administered daily to the mice and the treatment started 2 days after the injection of the cancer cells. A significant decrease in the tumor growth rate was observed in mice treated with these two drugs in comparison with untreated mice from day 12 to day 20 after injection of the tumor cells (Fig. 2a). Twenty days following the injection of the cancer cells, the volume of the tumor was reduced by more than $80 \%$ in the treated groups, with a mean volume of $0.86 \mathrm{~mm}^{3}$ for the control group versus 0.13 and $0.10 \mathrm{~mm}^{3}$ when LMWH or Clopidogrel were used, respectively (Fig. 2b). However, the tumor growth rates (Fig. $2 c$ ) and the volumes of the tumors 20 days post-injection (Fig. $2 d$ ) were not significantly different in mice treated with Clopidogrel.
We next compared the kinetics of thrombosis following laser-induced injury in mice treated with Clopidogrel or LMWH and bearing Panc02-HighTF tumors for 20 days. The treatment with LMWH significantly reduced the rate of thrombus formation in mice bearing a tumor in comparison with tumor-free mice (Fig. $3 a$ ). In contrast, treatment with Clopidogrel induced a phenotype similar to that observed in tumor-free mice (Fig. $3 b$ ). These results indicate that a direct inhibition of platelet activation may constitute an efficient strategy to treat thrombosis associated with cancer.

Clopidogrel prevents the accumulation of cancer cellderived microparticles at the site of thrombosis

Previously result from our group demonstrated that cancer cell-derived microparticles accumulation at the site of thrombosis is responsible for the thrombotic phenotype observed in mice with cancer. ${ }^{13}$ We hypothesis that a treatment with an antiplatelet drug may affect the accumulation of cancer cell-derived microparticles at the site of thrombosis. Before injury but after their infusion into the bloodstream, 
$a$
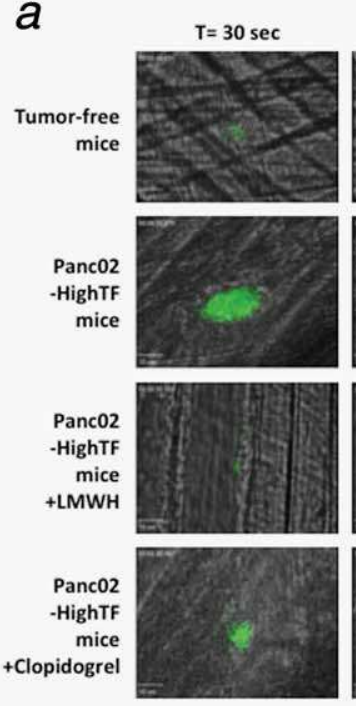

$\mathrm{T}=\mathbf{5 0} \mathrm{sec}$
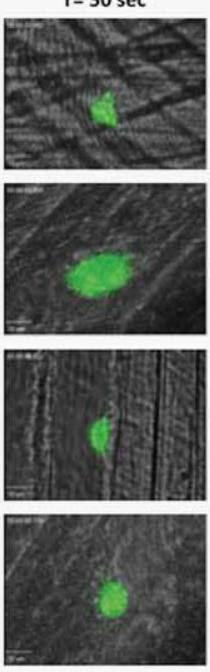
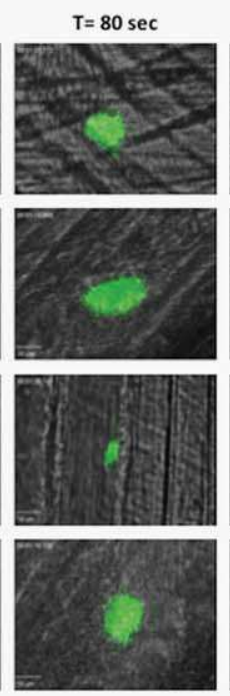
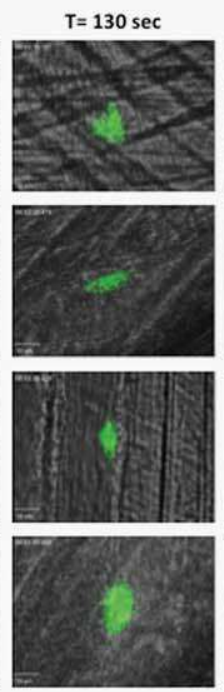

$\mathrm{T}=180 \mathrm{sec}$
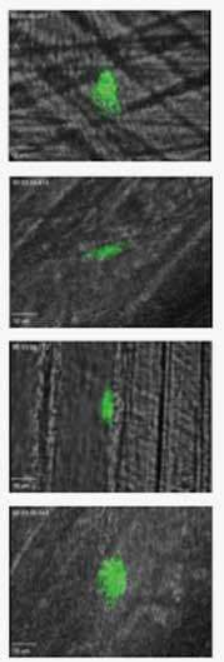

\section{b}

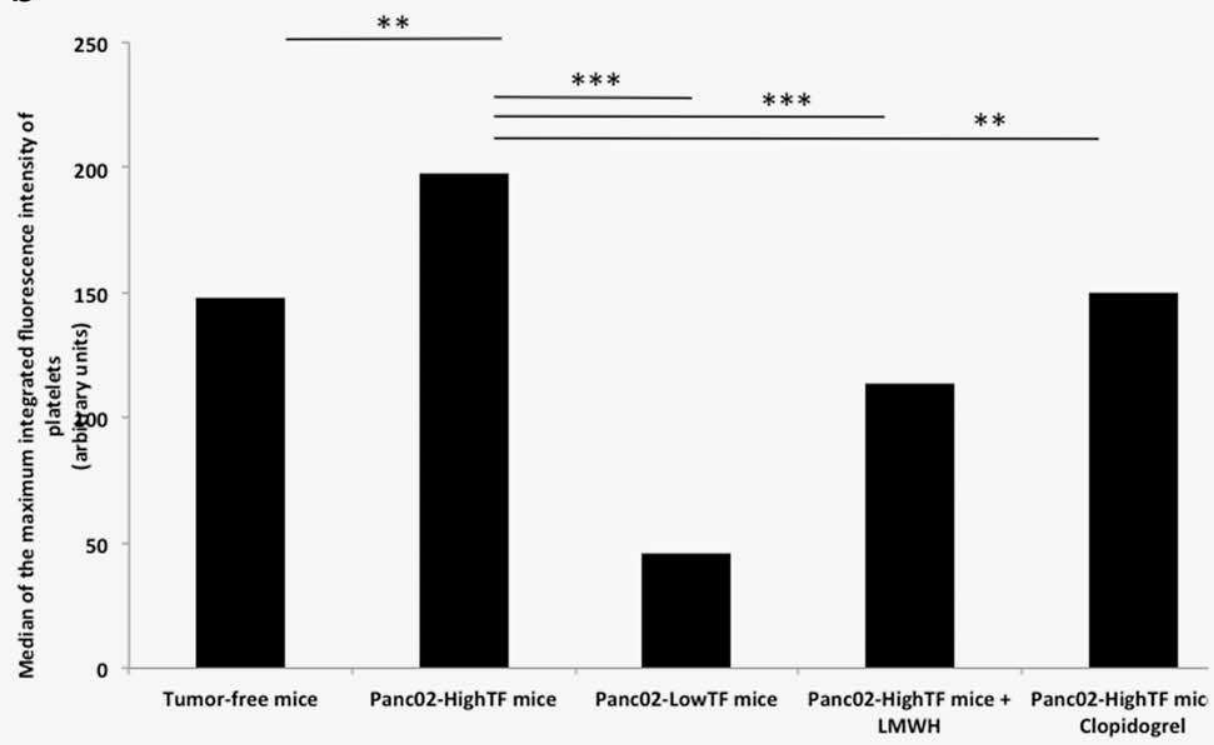

Figure 3. Treatment with Clopidogrel reduces thrombosis without affecting the bleeding time. (a) Representative images of thrombus formation in tumor-free mice and mice bearing Panc02-HighTF tumors with or without treatment with Clopidogrel or LMWH. (b) The median maximum integrated fluorescence intensity of the platelet thrombi in tumor-free mice ( 43 thrombi in 4 mice) or in mice bearing Panc02-HighTF tumors in the absence ( 46 thrombi in 4 mice) or presence of treatment with Clopidogrel ( 44 thrombi in 4 mice) or LMWH ( 38 thrombi in 3 mice). ${ }^{\star \star} p<0.01 ;{ }^{\star \star \star} p<0.001$. [Color figure can be viewed in the online issue, which is available at wileyonlinelibrary.com.]

exogenous labeled cancer cell-derived microparticles were detected in the cremaster microcirculation of untreated and Clopidogrel-treated mice (Fig. 4a, left panel). However, following the injury, cancer cell-derived microparticles accumulated at the site of the thrombus formation only in untreated mice (Fig. $4 a$, right panel), suggesting that treatment by Clopidogrel prevents the accumulation of cancer cell-derived MPs at the site of thrombosis. These results were confirmed by tracking endogenously shed cancer-cell derived microparticles using Panc02-GFP cells injected subcutaneously in a mouse. ${ }^{13}$ Endogenous microparticles circulate in the bloodstream of a mouse bearing a Panc02-GFP tumor and accu- mulate at the site of injury (Fig. 4b, left panel). The treatment of mice with Clopidogrel prevents this interaction, although microparticles were still detected in the bloodstream (Fig. $4 b$, right panel).

To determine the molecular pathways involved in the accumulation of cancer-cell derived microparticles at the site of thrombosis, we next look for the proteins expressed at their surface. In addition to PSGL-1, ${ }^{13}$ the integrin subunits CD51 $(\alpha \mathrm{v}), \operatorname{CD} 29(\beta 1)$ and $\operatorname{CD} 61(\beta 3)$ were identically highly expressed at the surface of the Panc02-low and highTF MPs (Fig. 4c). The number of microparticles expressing CD29, CD51 and CD61 produced per cell was similar between the 
a

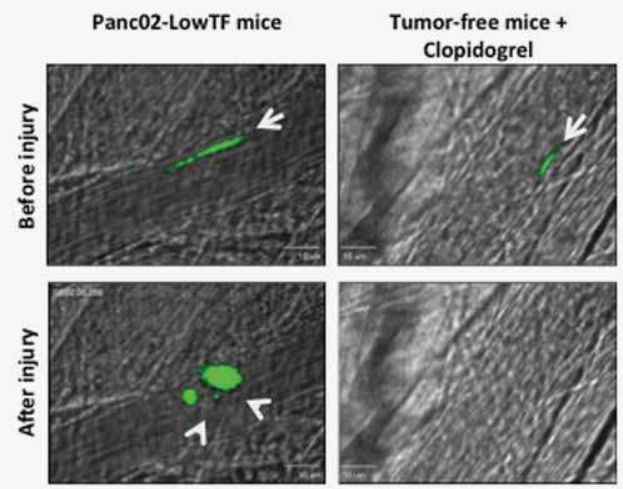

$b$
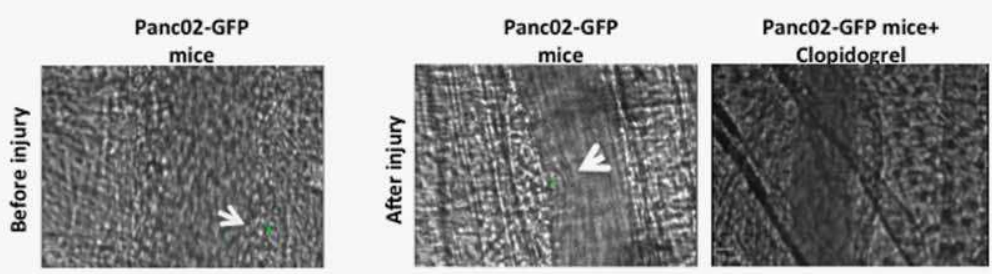

C
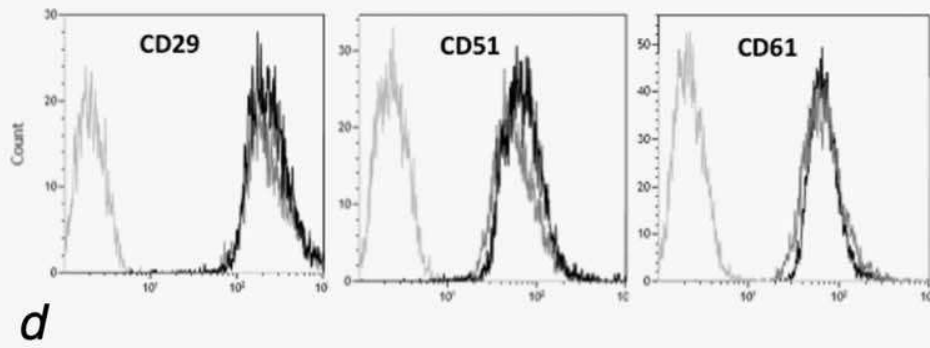

$\square$ Panc02-HighTF cells
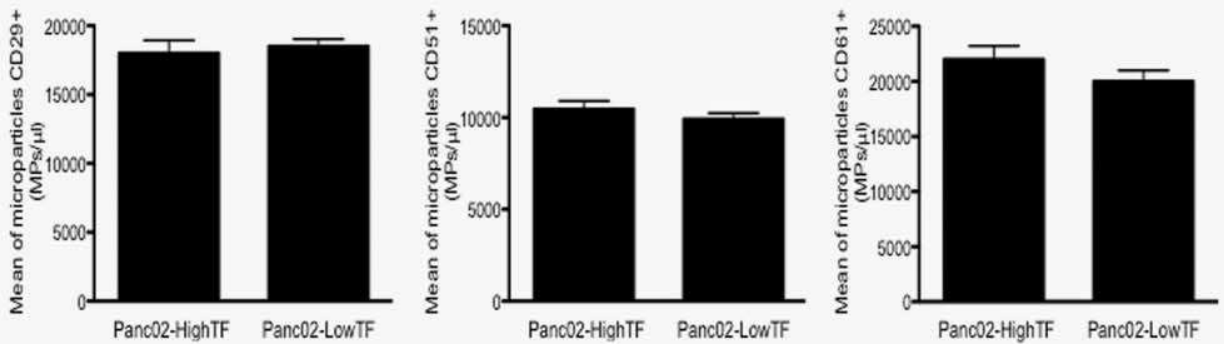

Figure 4. Clopidogrel prevents the $\alpha \mathrm{v} \beta 1$ - and $\alpha \mathrm{v} \beta 3$-dependent accumulation of cancer cell-derived microparticles at the site of thrombosis. $(a, b)$ Representative images of exogenously labeled and infused Panc02 microparticles in tumor-free mice $(a)$ and endogenously formed circulating Panc02-GFP microparticles in mice bearing an ectopic Panc02-GFP tumor (b) (in green) before and after injury in non-treated or Clopidogrel treated mice (observed in almost three independent experiments). (d) Representative flow cytometry analysis of CD29 ( $\beta 1$ ), CD51 and CD61 ( 33 ) expression at the surface of Panc02-High and -Low TF cells. (e) Number of microparticles expressed by $5 \times 10^{8}$ Panc02-High and -Low TF cells and double positive for Annexin V and CD29, CD51 or CD61. [Color figure can be viewed in the online issue, which is available at wileyonlinelibrary.com.]

Panc02-Low and -HighTF (Fig. 4e). These results suggest that Panc02-derived microparticles may directly bind to fibrinogen at the site of thrombosis. Under in vitro flowing conditions, the addition of RGDV, a competitive inhibitor of the interaction between the $\alpha \mathrm{v} \beta 1 / \beta 3$ integrins and their ligands, inhibited the adhesion of Panc02-Low and -HighTF microparticles to fibrinogen (Fig. 5a). This result was confirmed in vivo, following laser-induced injury (Fig. $5 b$, upper panel). In mice bearing a Panc02-GFP tumor, depletion of circulating platelets by injec- tion of R300 antibody ${ }^{23}$ prevented the adhesion of circulating Panc02-GFP microparticles at the site of injury (Fig. 5b, low panel). Last, when mice bearing Panc02 tumors were treated with Clopidogrel, the quantity of P-selectin, mainly expressed by activated platelets present at the site of injury was fourfold less important in comparison with untreated mice (Fig. 5c). Taking together these results indicate that Panc02 cancer cellderived microparticles firmly adhere at the site of injury to fibrinogen present on activated platelets forming a thrombus. 

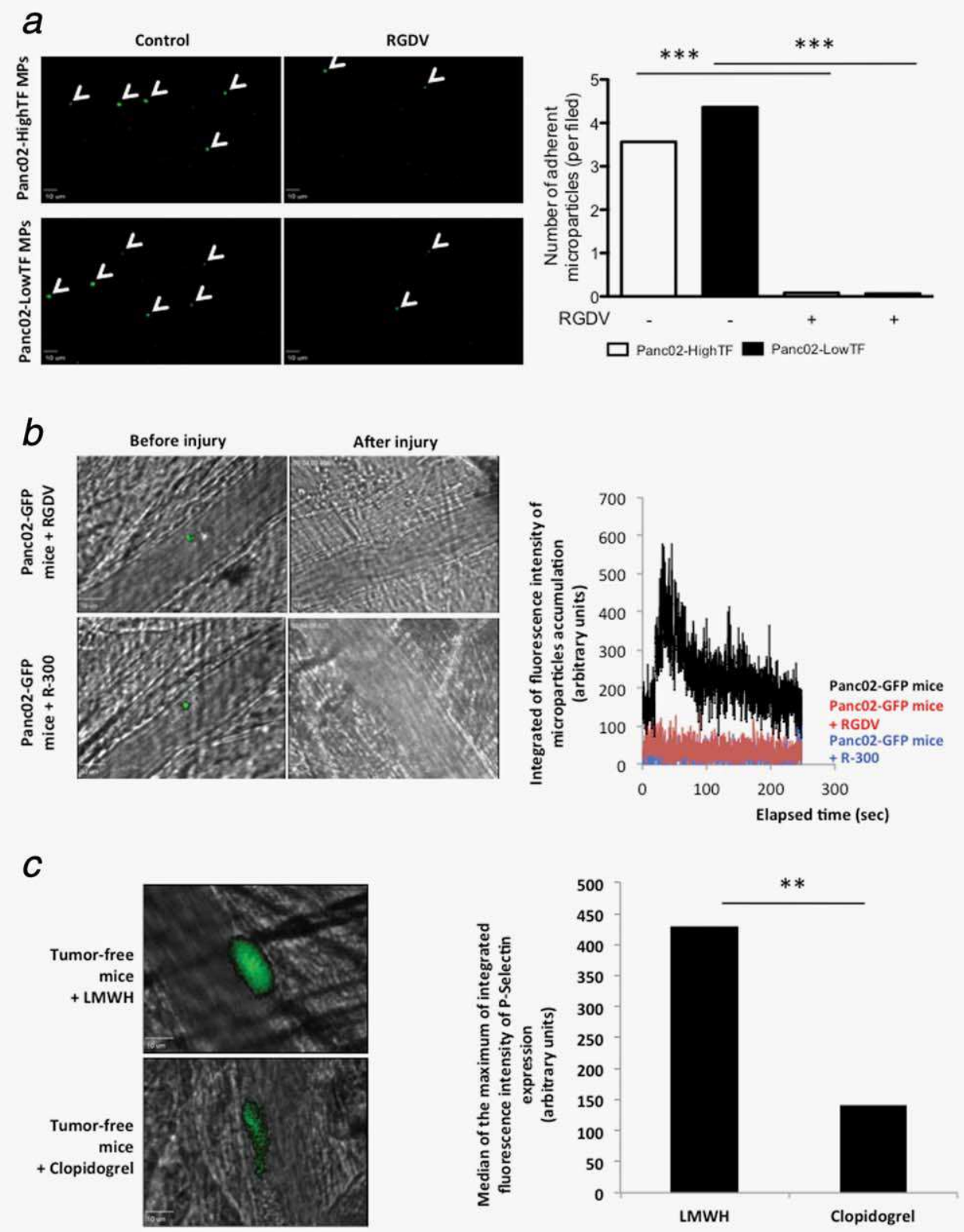

Figure 5. Panc02-derived microparticles bind to fibrinogen and platelets in vitro and in vivo. (a) Representative pictures (Left panel) or median number (right panel, median of three independent experiments) of adherent microparticles on a fibrinogen matrix in in vitro flow experiments performed after injection of $2 \times 10^{5}$ Panc02-HighTF (upper panel) and Panc02-LowTF (lower panel) microparticles in absence (left panel) or presence of RGDV ( $5 \mathrm{mg} / \mathrm{mL}$ ). Microparticles are depicted in green (60× objective). (b) Representative pictures (left panel) and integrated fluorescence intensity (right panel) of Panc02-GFP microparticles accumulating at the site of injury in absence or presence of RGDV $(10 \mathrm{mg} / \mathrm{kg})$ or R-300 (2 $\mu \mathrm{g} / \mathrm{g})$. Representative of four independent experiments per condition. (c) Representative image of P-selectin accumulation (in green) in tumor-free mice treated with LMWH (c, top panel) or Clopidogrel (c, bottom panel) (observed in almost three independent experiments). The median maximum integrated fluorescence intensity of P-selectin accumulating in wild-type mice treated with LMWH or Clopidogrel ( 41 thrombi in 4 mice for each condition). ${ }^{\star \star} p<0.01$. [Color figure can be viewed in the online issue, which is available at wileyonlinelibrary.com.]

Interestingly, Panc02-high and lowTF cancer cellderived microparticles express both $\mathrm{TF}^{13}$ and TFPI (Fig. $6 a$ ), a biological inhibitor of the coagulation cascade, in an active form, as demonstrated by the assessment of the TFPI activity present at the surface of the Panc02-LowTF and Panc02-HighTF cells (Fig. 6b). We next compared fibrin generation at the site of injury in Panc02-HighTF and Panc02-LowTF cancer mice in the presence and absence of Clopidogrel. In wild-type mice, as previously described, ${ }^{24}$ fibrin deposition increased during the first $5 \mathrm{~min}$ after injury. This deposition of fibrin at the site of laser-induced injury was significantly greater $(p<0.01)$ in mice following 


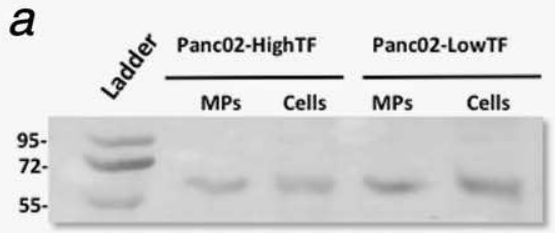

(kb)

C

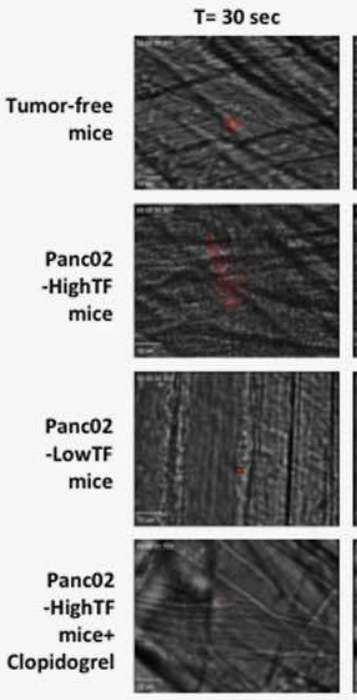

$d$
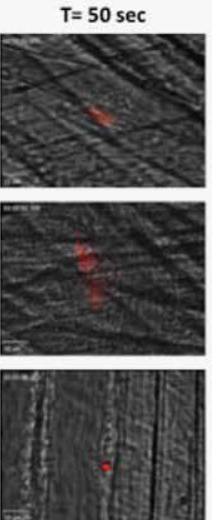
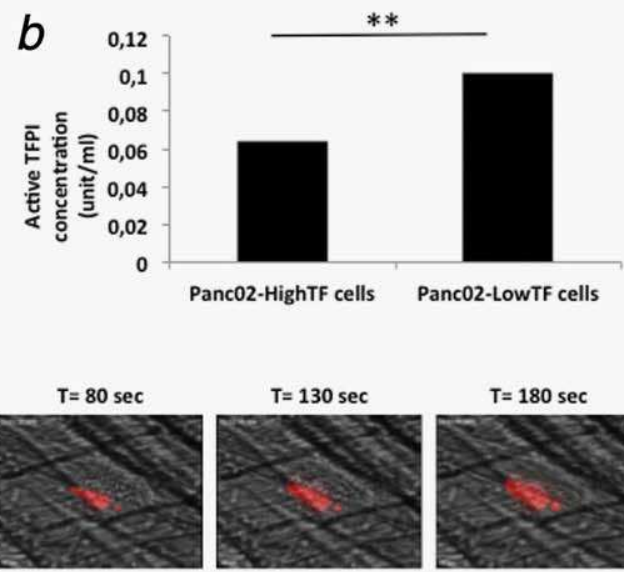

$\mathrm{T}=\mathbf{1 8 0 \mathrm { sec }}$
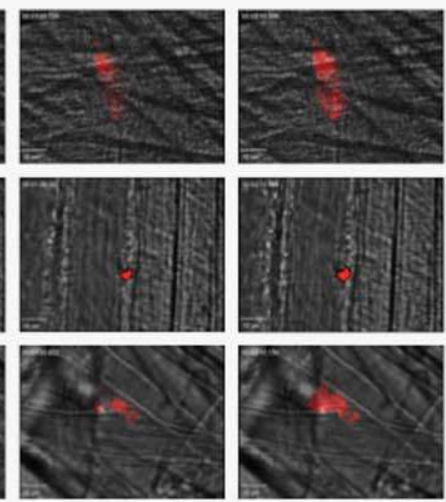

e
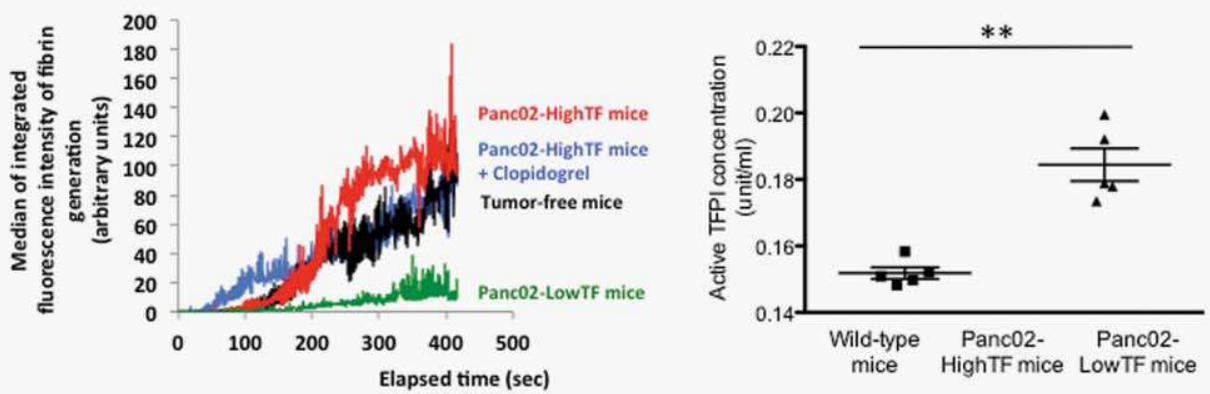

Figure 6. Inhibition of fibrin generation in mice bearing Panc02-LowTF tumors by cancer cell-derived microparticles expressing TFPI. (a) Western blot analysis of TFPI expression in Panc02-HighTF or Panc02-LowTF cells and microparticles (MP) extracts (80 $\mu \mathrm{g} / \mathrm{well})$. (b) TFPI activity (in units $/ \mathrm{mL}$ ) in Panc02-HighTF and Panc02-LowTF cells (mean of three independent experiments). (c) Representative image of fibrin accumulation at the site of laser-induced injury in tumor-free mice or mice bearing Panc02-High or Panc02-LowTF tumors and treated with Clopidogrel or left untreated. (d) Median integrated fluorescence intensity due to fibrin generation in tumor-free mice or mice bearing a Panc02-HighTF or Panc02-LowTF tumors and treated or not by Clopidogrel (44 thrombi in 4 mice for each condition). (e) Plasmatic TFPI activity (in units $/ \mathrm{mL}$ ) in mice bearing a Panc02-HighTF and Panc02-LowTF tumor (mean of three independent experiments). ${ }^{*} p<0.05$; ${ }^{\star \star} p<0.01$. [Color figure can be viewed in the online issue, which is available at wileyonlinelibrary.com.]

the injection of Panc02-HighTF cells than in wild-type mice. The treatment of these mice with Clopidogrel reduced the production of fibrin to a level comparable to that observed in wild-type mice (Figs. $6 c$ and $6 d$ ). When the TF expression was knocked down from Panc02, the production of fibrin was strongly reduced (Figs. $6 c$ and $6 d$ ) and the plasmatic activity of TFPI was significantly increased (Fig. 6e). We concluded that when cancer cells and cancer cell-derived microparticles express active TF, their incorporation to a growing thrombus via the binding of fibrinogen present on platelets participates in the generation of a thrombotic phenotype. When TF expression by cancer cells is knocked down, cancer cell microparticles are still incorporated at the site of thrombus formation, 
a
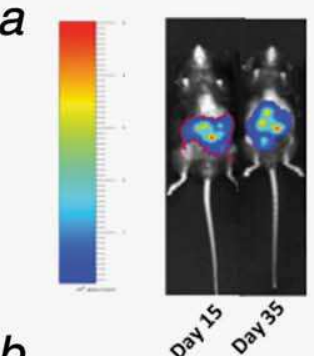

$b$

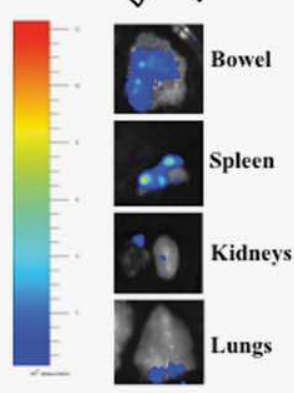

$C$
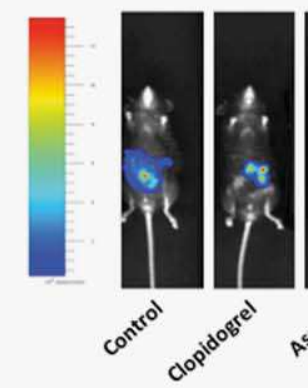
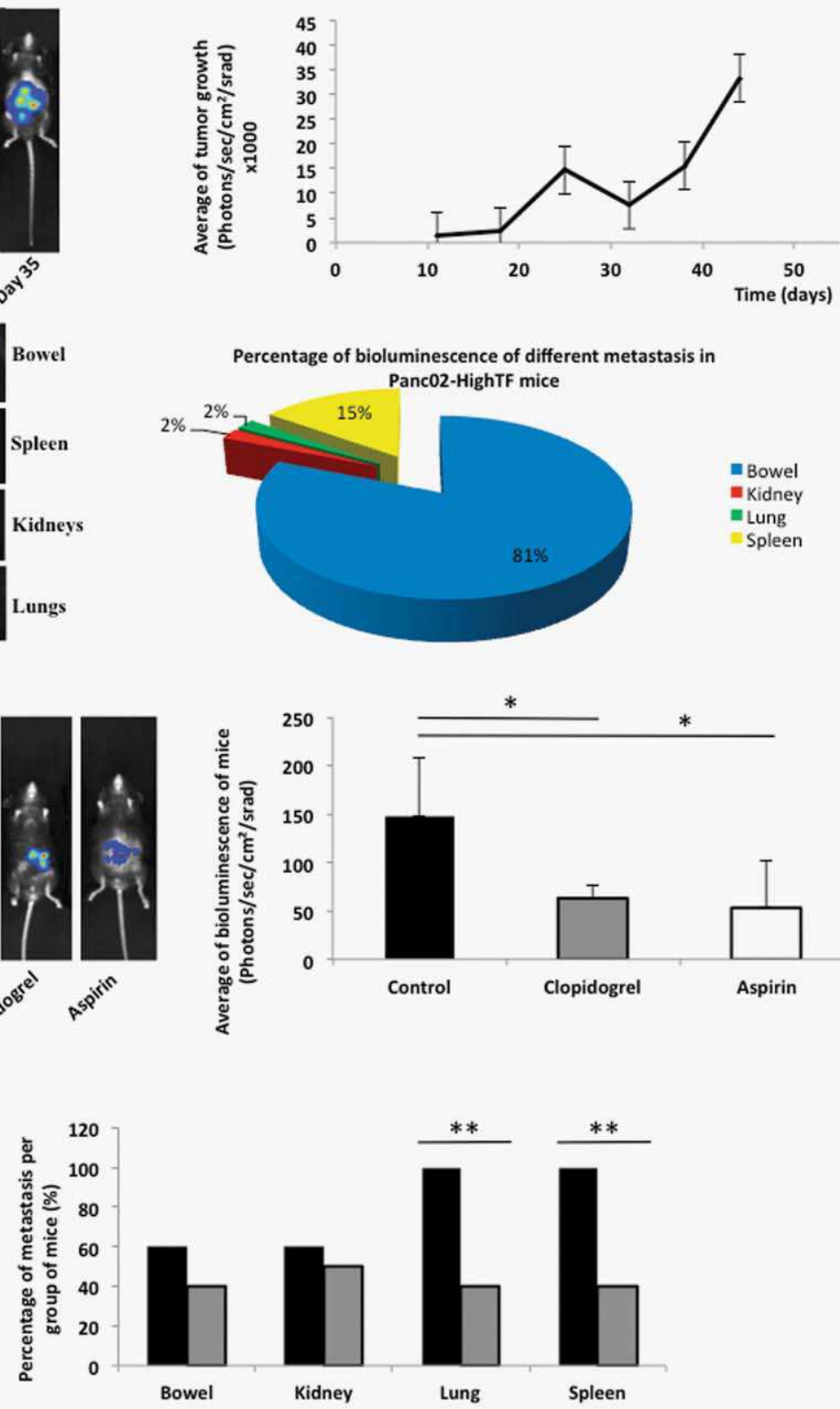

Figure 7. Quantification of tumor growth and metastasis generation in a syngeneic orthotopic model of pancreatic cancer with or without Clopidogrel or Aspirin treatment. (a, left panel) Representative images showing the bioluminescence signal at day 15 and day 35 (a, right panel). The graph depicts the average of the tumor growth of bioluminescent orthotopic pancreatic cancer in mice as function of time. ( $b$, left panel) Representative image of organs metastasis, ( $b$, right panel) the pie chart represents the percentage of the bioluminescence in different organs (bowel, kidneys, lungs and spleen) of wide-type mice ortopically implanted with panc02-HightTF. (c, left panel) Representative image of the bioluminescence signals of Panc02-HighTF tumors treated with Clopidogrel or Aspirin or left untreated at day 20. (c, right panel) The graph represents the average bioluminescence signal intensity for mice ortopically implanted with panc02-HightTF non treated (control; $N=8)$ or treated with ether Clopidogrel $(N=11)$ or Aspirin $(N=10)$. (d) Percent bioluminescence by type of metastasis (bowel, kidney, lung and spleen). This experiment was performed in six mice per group. ${ }^{\star} p<0.05$. [Color figure can be viewed in the online issue, which is available at wileyonlinelibrary.com.]

but there is reduced activation of TF, thus inhibiting fibrin generation and thrombus formation by bringing TFPI to the site of injury. A treatment by Clopidogrel prevents the accumulation of cancer cell-derived microparticles by inhibition of platelets.

\section{Aspirin and Clopidogrel prevent tumor growth and reduce metastasis in a syngeneic orthotopic model of pancreatic cancer}

Based on our observations, we hypothesized that the inhibition of platelet activation to reduce both thrombosis 
associated with cancer and tumor growth could constitute an interesting therapeutic strategy to treat cancer and thrombosis. To test this hypothesis, we developed a syngeneic orthotopic model of pancreatic cancer by stably transfecting Panc02 cells with a gene encoding luciferase before implantation into the pancreases of wild-type mice. ${ }^{18}$ This cellular clone was named Panc02-Luci. The development of the tumors and the formation of metastasis were monitored over a period of up to 2 months in mice. Using an in vivo imaging system based on a bioluminescence technology, we were able to noninvasively monitor and measure the orthotopic tumor growth and the development of metastases in the whole mouse. Figure $7 a$ shows the growth of the Panc02Luci tumors in wild-type mice. The quantity of Panc02-Luci cells present in the mice increased over time (Fig. 7a, left panel), indicating an increase in the tumor size that can be quantified by luminescence (Fig. $7 a$, right panel). At the end of the experiment, we detected and quantified the presence of luciferase-expressing tumor cells in each harvested organ, and we observed that wild-type mice developed metastases in the bowel, spleen and kidneys and, after 30 days, in the lungs (Fig. $7 b$, left panel). The greatest luminescence intensity, corresponding to the number of Panc02-Luci cells, was observed in the bowel (Fig. $7 b$, right panel). In vitro, Aspirin and Clopidogrel did not affect the growth of the Panc02-Luci clone (data not shown). In vivo, when mice were treated with Clopidogrel or Aspirin daily for 28 days, the growth of the primary tumor was significantly reduced; 35 days after the injection of the Panc02-Luci cells into the pancreas, a significant difference in the bioluminescence signal was observed between control and Clopidogrel- or Aspirin-treated mice (Fig. $7 c$, left panel). This difference was observed when the whole-body luminescence signals were detected (Fig. $7 c$, right panel) as well as when we focused on the development of metastases (Fig. 7d). Although metastases were detected in the lungs and spleens of $100 \%$ of the untreated mice, only $40 \%$ of the mice treated with Clopidogrel or Aspirin developed metastases in these organs (Fig. $7 d$ ). Together with the effects of anti-platelet drugs on thrombosis, these results indicate that Clopidogrel and Aspirin may represent promising therapeutic drugs to limit thrombosis and reduce the development of tumors and metastases.

\section{Discussion}

The goal of our study was to determine the effect of anti coagulant and anti platelet strategies on thrombosis and tumor development in mice developing a pancreatic cancer. We show that inhibition of the expression of TF by cancer cells leads to a decrease of platelet-rich thrombus formation and strongly diminishes the growth of the tumor. The knockdown of TF expressed by cancer cells also strongly affects the bleeding time and the activation of the blood coagulation cascade, mainly via the interaction of cancer cell-derived microparticles expressing TFPI, $\alpha v \beta 1$ and $\alpha v \beta 3$ with fibrinogen and platelet aggregates. When platelet activation is directly inhibited using Clopidogrel, thrombus formation is reduced without affecting the bleeding time and cancer cells derived microparticles do not accumulate at the site of injury. Treatment by Clopidogrel also significantly reduces the growth of the tumor. Although the models and the type of cancer studied are different, these results are in accordance with the previous studies showing an effect of Clopidogrel treatment on the growth of hepatocellular carcinoma or mammary carcinoma. ${ }^{25,26}$ Altogether these results suggest that an antiplatelet strategy may be efficient to reduce the tumor growth independently to the type of cancer. We showed in this study in a syngeneic orthotopic model of pancreatic cancer that, two antiplatelet drugs, Clopidogrel and Aspirin, significantly reduce the size of the tumor and inhibit the development of metastases. Together, our results indicate that an anti-platelet strategy may efficiently treat thrombosis associated with cancer and reduce the progression of pancreatic cancer in mice.

In addition to its functions in coagulation, TF has also been reported to induce the transcriptional activation of different growth factors, including VEGF, following the phosphorylation and binding of its cytoplasmic tail to filamin. ${ }^{27,28}$ This intracellular pathway may also participate in the growth of the tumor and angiogenesis. ${ }^{29}$ Furthermore, TF expression has also been reported to influence the motility, survival and proliferation of cancer cells via the activation of PAR-1 and PAR$2,^{30,31}$ although in the present study, the proliferation of Panc02 cells was not affected by the inhibition of TF expression. Cancer cells may directly activate platelets by secreting ADP, thromboxane A2 and MMP-2 (matrix metalloproteinase 2) and by expressing platelet ligands, such as PSGL-1, on their surfaces. $^{32-34}$ This leads to the aggregation of platelets in the bloodstream around cancer cells, a process that has been reported to protect cancer cells from destruction by the immune system and from blood shear stress. This aggregation also facilitates interactions of cancer cells with the endothelium. ${ }^{35}$ However, the direct involvement of these platelet agonists was not demonstrated in vivo in an orthotopic syngeneic mouse model. When mice were treated with LMWH, a decrease in tumor development similar to that obtained when pathological TF expression was knocked down was observed. Additionally, treatment with Clopidogrel did not significantly affect the growth of the tumors in the Panc02-LowTF group or in the Panc02-HighTF group treated with LMWH (data not shown). These results strongly suggest that the activation of platelets is involved in the growth of the tumor and that the main activator of platelets is TF expressed by cancer cells, not ADP or thromboxane A2. These secondary agonists may be involved when secreted as a consequence of platelet activation generated by thrombin through a TF-dependent pathway.

Lastly, these agonists may not play an important role directly in the growth of tumors but may play important roles in the formation of metastases when cancer cells are present in the bloodstream.

The injection of LMWH was recently described as a potent treatment for thrombosis associated with cancer. 
Indeed, LMWH acts on the coagulation cascade and prevents interactions between $\mathrm{P}$-selectin and its ligands. ${ }^{36}$ Different clinical studies have been performed, but to date, none have shown a clear benefit of such treatment for thrombosis associated with cancer. We showed that the use of LMWH in mice affected not only thrombosis but also hemostasis. In humans, different studies have shown an increased risk of bleeding associated with treatment with LMWH. This increased risk may be due to the presence of TFPI on cancer cell-derived microparticles. Surprisingly, the use of antiplatelet drugs to treat thrombosis associated with cancer has never been evaluated in a syngeneic orthotopic mice model. Our results for the effects of Clopidogrel on tumor growth were similar to those observed when LMWH was injected or when TF expression was knocked down. However, Clopidogrel, at the concentration used, did not induce a hemorrhagic-like phenotype in mice, as shown by the observed kinetics of platelet and fibrin generation. We have previously shown that circulating TF-bearing cancer cell-derived microparticles play an important role in thrombosis associated with cancer. ${ }^{13}$ Anti-platelet drugs, but not LMWH, may efficiently affect thrombosis induced by cancer cells without affecting hemostasis by limiting the interactions of circulating cancer cellderived microparticles. Furthermore, in a syngeneic ortho- topic model of pancreatic cancer, Clopidogrel and Aspirin strongly inhibited the formation of metastasis. Recently, a meta-analysis demonstrated the short-term benefit of daily Aspirin on cancer incidence. ${ }^{37}$ This finding has been confirmed by observational studies showing that the regular use of Aspirin reduces the long-term risk of several cancers and the risk of distant metastasis. ${ }^{38}$ However, in two randomized studies, there were no benefits of low-dose Aspirin in the primary prevention of cancer. ${ }^{39,40}$ Here, we observed similar effects for Aspirin and Clopidogrel. However, the molecular pathways involved in the effects of Aspirin and Clopidogrel on the reductions in tumor development and metastasis remain unidentified.

Together, these results strongly suggest that the use of anti-platelet drugs may be an efficient alternative strategy to the use of LMWH to treat patients suffering from thrombosis associated with cancer and to limit development of tumors.

\section{Acknowledgements}

The authors are indebted to Stephane Robert (Inserm UMR-S1076) for technical assistance. They also thank Pr. Dominique Farge-Bancel and Pr. Philippe Debourdeau for critical scientific review of the work, and Dr. Ben Atkinson (Intelligent Imaging Innovation) for technical support of the intravital system.

\section{References}

1. Sack GH Jr, Levin J, Bell WR. Trousseau's syndrome and other manifestations of chronic disseminated coagulopathy in patients with neoplasms: clinical, pathophysiologic, and therapeutic features. Medicine (Baltimore) 1977;56:1-37.

2. Blom JW, Vanderschoot JPM, Oostindiër MJ, et al. Incidence of venous thrombosis in a large cohort of 66,329 cancer patients: results of a record linkage study. J Thromb Haemost JTH 2006;4:529-35.

3. White RH, Chew HK, Zhou H, et al. Incidence of venous thromboembolism in the year before the diagnosis of cancer in 528,693 adults. Arch Intern Med 2005;165:1782-7.

4. Alcalay A, Wun T, Khatri V, et al. Venous thromboembolism in patients with colorectal cancer: incidence and effect on survival. J Clin Oncol Off J Am Soc Clin Oncol. 2006;24:

1112-8.

5. Guzmán-Uribe P, Rosas-López A, Zepeda-León J, et al. Incidence of thrombosis in adults with acute leukemia: a single center experience in Mexico. Rev Investig Clínica Organo Hosp Enfermedades Nutr 2013;65:130-40.

6. Neoptolemos JP, Stocken DD, Dunn JA, et al. Influence of resection margins on survival for patients with pancreatic cancer treated by adjuvant chemoradiation and/or chemotherapy in the ESPAC-1 randomized controlled trial. Ann Surg 2001;234:758-68

7. Walker G, Xenophontos M, Chen L, et al. Longterm efficacy and safety of exemestane in the treatment of breast cancer. Patient Prefer Adherence 2013;7:245-58.

8. Sørensen HT, Mellemkjaer L, Olsen JH, et al. Prognosis of cancers associated with venous thromboembolism. N Engl J Med. 2000;343:1846-50.
9. Gasic GJ, Koch PA, Hsu B, et al. Thrombogenic activity of mouse and human tumors: effects on platelets, coagulation, and fibrinolysis, and possible significance for metastases. Z Für Krebsforsch Klin Onkol Cancer Res Clin Oncol 1976;86:26377.

10. Sierko E, Wojtukiewicz MZ. Inhibition of platelet function: does it offer a chance of better cancer progression control? Semin Thromb Hemost 2007; 33:712-21.

11. Schaffner F, Ruf W. Tissue factor and PAR2 signaling in the tumor microenvironment. Arterioscler Thromb Vasc Biol 2009;29: 1999-2004.

12. Winter PC. The pathogenesis of venous thromboembolism in cancer: emerging links with tumour biology. Hematol Oncol 2006;24:126-33.

13. Thomas GM, Panicot-Dubois L, Lacroix R, et al. Cancer cell-derived microparticles bearing Pselectin glycoprotein ligand 1 accelerate thrombus formation in vivo. J Exp Med 2009;206:1913-27.

14. Atkinson BT, Jasuja R, Chen VM, et al. Laserinduced endothelial cell activation supports fibrin formation. Blood 2010;116:4675-83.

15. Corbett TH, Roberts BJ, Leopold WR, et al. Induction and chemotherapeutic response of two transplantable ductal adenocarcinomas of the pancreas in C57BL/6 mice. Cancer Res 1984;44: 717-26.

16. Panicot-Dubois L, Thomas GM, Furie BC, et al. Bile salt-dependent lipase interacts with platelet CXCR4 and modulates thrombus formation in mice and humans. J Clin Invest 2007;117:3708-19.

17. Hubert L, Darbousset R, Panicot-Dubois L, Robert S, Sabatier F, Fallague K, et al. Neutrophils recruit and activate Human Endothelial Colony Forming Cells at the site of vessel injury via PSGL-1 and L-Selectin. J Thromb Haemost 2014 Mar 8; DOI: 10.1111/jth.12551.

18. Kim MP, Evans DB, Wang H, et al. Generation of orthotopic and heterotopic human pancreatic cancer xenografts in immunodeficient mice. Nat Protoc 2009;4:1670-80.

19. Dubois C, Panicot-Dubois L, Merrill-Skoloff G, et al. Glycoprotein VI-dependent and -independent pathways of thrombus formation in vivo. Blood 2006;107:3902-6.

20. Dubois C, Panicot-Dubois L, Gainor JF, et al. Thrombin-initiated platelet activation in vivo is vWF independent during thrombus formation in a laser injury model. J Clin Invest 2007;117:953-60.

21. Yu JL, May L, Lhotak V, et al. Oncogenic events regulate tissue factor expression in colorectal cancer cells: implications for tumor progression and angiogenesis. Blood 2005;105:1734-41.

22. De Oliveira ADS, Lima LG, Mariano-Oliveira A, et al. Inhibition of tissue factor by ixolaris reduces primary tumor growth and experimental metastasis in a murine model of melanoma. Thromb Res 2012;130:e163-170.

23. Darbousset R, Thomas MG, Mezouar S, et al. Tissue factor-positive neutrophils bind to injured endothelial wall and initiate thrombus formation. Blood 2012;120:2133-43.

24. Falati S, Liu Q, Gross P, et al. Accumulation of tissue factor into developing thrombi in vivo is dependent upon microparticle P-selectin glycoprotein ligand 1 and platelet P-selectin. J Exp Med 2003;197:1585-98.

25. Sitia G, Aiolfi R, Di Lucia P, et al. Antiplatelet therapy prevents hepatocellular carcinoma and improves survival in a mouse model of chronic hepatitis B. Proc Natl Acad Sci USA 2012;109: E2165-72. 
26. Chiodoni C, Iezzi M, Guiducci C, et al. Triggering CD40 on endothelial cells contributes to tumor growth. J Exp Med 2006; 203:2441-50.

27. Ruf W, Yokota N, Schaffner F. Tissue factor in cancer progression and angiogenesis. Thromb Res 2010;125:S36-38.

28. Ott I, Fischer EG, Miyagi Y, et al. A role for tis sue factor in cell adhesion and migration mediated by interaction with actin-binding protein 280. J Cell Biol 1998;140:1241-53.

29. Zucker S, Mirza H, Conner CE, et al. Vascular endothelial growth factor induces tissue factor and matrix metalloproteinase production in endothelial cells: conversion of prothrombin to thrombin results in progelatinase A activation and cell proliferation. Int J Cancer 1998;75:780-6.

30. Carney DH, Herbosa GJ, Stiernberg J, et al. Double-signal hypothesis for thrombin initiation of cell proliferation. Semin Thromb Hemost 1986;12: 231-40.

31. Darmoul D, Gratio V, Devaud H, et al. Aberrant expression and activation of the thrombin recep- tor protease-activated receptor-1 induces cell proliferation and motility in human colon cancer cells. Am J Pathol 2003;162:1503-13.

32. Camez A, Dupuy E, Bellucci S, et al. Human platelet-tumor cell interactions vary with the tumor cell lines. Invasion Metastasis 1986;6:32134.

33. Jurasz P, Sawicki G, Duszyk M, et al. Matrix metalloproteinase 2 in tumor cell-induced platelet aggregation: regulation by nitric oxide. Cancer Res 2001;61:376-82.

34. Alonso-Escolano D, Strongin AY, Chung AW, et al. Membrane type-1 matrix metalloproteinase stimulates tumour cell-induced platelet aggregation: role of receptor glycoproteins. Br J Pharmacol 2004;141:241-52.

35. Matsui $\mathrm{Y}$, Amano $\mathrm{H}$, Ito $\mathrm{Y}$, et al.

Thromboxane A2 receptor signaling facilitates tumor colonization through P-selectin-mediated interaction of tumor cells with platelets and endothelial cells. Cancer Sci 2012;103: $700-7$.
36. Maugeri N, Di Fabio G, Barbanti M, et al. Parnaparin, a low-molecular-weight heparin, prevents P-selectin-dependent formation of plateletleukocyte aggregates in human whole blood. Thromb Haemost 2007;97:965-73.

37. Rothwell PM, Price JF, Fowkes FG, et al. Shortterm effects of daily Aspirin on cancer incidence, mortality, and non-vascular death: analysis of the time course of risks and benefits in 51 randomised controlled trials. Lancet 2012;379:1602-12.

38. Rothwell PM, Wilson M, Price JF, et al. Effect of daily Aspirin on risk of cancer metastasis: a study of incident cancers during randomised controlled trials. Lancet 2012;379:1591-601.

39. Stürmer T, Glynn RJ, Lee IM, et al. Aspirin use and colorectal cancer: post-trial follow-up data from the Physicians' Health Study. Ann Intern Med 1998;128:713-20.

40. Cook NR, Lee I-M, Gaziano JM, et al. Low-dose Aspirin in the primary prevention of cancer: the Women's Health Study: a randomized controlled trial. JAMA J Am Med Assoc 2005;294:47-55. 